$$
\text { "takaci" — 2008/9/1 — 18:12 — page } 111 \text { — \#1 }
$$

\title{
The influence of computer on examining trigonometric functions
}

\author{
Djurdjica Takači, Radivoje Stojković, Jasminka Radovanović
}

\begin{abstract}
In this paper the influence of computer on examining trigonometric functions was analyzed throughout the results questionnaire. The students, as usual, had to examine two trigonometric functions, both were given with the appropriate instructions. Three groups were tested. Two of those three groups were prepared with the help of computer and the third one was taught without computer. From the analysis of the questionnaire it follows that the computer has a great influence on understanding of the connections between the graph and very complex calculations.
\end{abstract}

Key words and phrases: CAS, teaching-learning process, trigonometry.

ZDM Subject Classification: D44, G44, I44, U74.

\section{Introduction}

It is known that the trigonometry is the most difficult part in the high school education. The students have difficulties remembering and applying trigonometric identities properly. Therefore, the examining and drawing trigonometric functions in the last grade of high school is almost omitted.

Last year the authors, have opportunity to work in computer laboratory, with the fourth grade students in High School "Jovan Jovanović'-Zmaj", and with the first year university students whose major is physics in Novi Sad, in Serbia. The teacher had a computer and video beam and the students had computer, as well. The students were familiar with three programme packages: Mathematica, Scientific Workplace, and GeoGebra. During these lectures the teacher used Scientific

Copyright (C) 2008 by University of Debrecen 
Workplace number 3, as well as the students, because this programme package is quite suitable for teaching and learning. Working in and handling this programme on computer is very easy to accept, it looks like writing on the blackboard and therefore the main students' and teachers' concentration is on the given example.

The computer was used as the help of the usual classical calculation in the course of Calculus in the third and the fourth grade, and each content as the limits of sequences, limits of functions, continuity of functions, derivatives, integrals, and their applications are taught with the computer. Namely, the computer, in particular the programme package Scientific Workplace and Mathematica, were used not only for the animations in the introduction to these difficult contents, but also as a good assistant of the teacher. The students were taught almost usually, rewriting tasks into their notebooks from the blackboard in the classical classrooms. Several times a month (one to three times), during one and a half hour lesson, they were able to use computer laboratory and to take part in the new ways of communication, combining hand and computer calculations. Each time they were given their homework, which was supposed to be done in the notebooks as usual.

This year 2006 (December) the examining functions was elaborated in the computer laboratory combining classical (usual) and computer treatment. The rational and trigonometric functions were analyzed. The teacher together with the students examined the graphs of the following functions:

$$
\begin{array}{ll}
f(x)=\cos x+\frac{1}{2} \cos 2 x, & f(x)=\sin x+\frac{1}{2} \sin 2 x, \\
f(x)=\cos ^{3} x+\sin ^{3} x, & f(x)=\sin x \sin 3 x .
\end{array}
$$

First, the analytical expression of the functions was written, then its graph was drawn, and after that the functions were examined. The classical procedure, (each point as domain, zeroes, the sign, the extremes, the monotonicity, the properties involved by the second derivative) was helped by the computer and all advantages of such examining were marked and discussed. During such analysis we were faced with new difficulties caused by programme which we used and they were pointed out and removed with the classical procedure. At the end of the lesson the students were given a few similar functions to do at home. They could use computer, but they could also apply the classical procedure. In the paper [5], the authors expose such examination of trigonometric functions by using programme package Scientific Workplace. 


$$
\text { "takaci" — 2008/9/1 — 18:12 — page } 113-\# 3
$$

Next week the high school students (not university students) were analyzing separately on computer the functions $f(x)=\cos x+\frac{1}{2} \sin 2 x$, and $f(x)=\sin 4 x-$ $4 \sin x$.

After a month they did their written task in which they had to examine classically two trigonometric functions. The first function was given with the graph and with the first and the second derivatives and the second function had instructions only. The same questionnaire was given to the high school (I group) and university students (II group) where the lessons were organized with the computer and also to one group (III group) of high school students who examined trigonometric functions classically. Both high school groups (I and III) were from the fourth grade, they had the same teacher, and by teachers opinion they had almost similar abilities for working mathematical problems and exercises.

In this paper we analyze the results of all three groups separately, and also we compared them in the last section. It can be seen that the students who used computer obtained much better results, than students who did not use the computer.

The idea for mentioned considerations came from papers [6], and [7]. In the papers [2], and [3], the programme package Scientific Workplace was used as a help for teaching continuity and limits, respectively. In [4], the results of the test on continuity was analyzed. The aim of the test in [4], was to check the students knowledge of continuity after the visual presentation exposed [3].

\section{The questionnaire}

The questionnaire was given in the following form:

(1) Examine the function $f(x)=\sin ^{3} x+\cos ^{3} x$.

Instructions: Show that

- the given function $f$ can be written in the form:

$$
f(x)=(\sin x+\cos x)\left(1-\frac{\sin 2 x}{2}\right) ;
$$

- the first derivative of $f$ can be written in the form:

$$
f^{\prime}(x)=3 \sin x \cos x(\sin x-\cos x) ;
$$

- the second derivative of $f$ can be written in the form:

$$
f^{\prime \prime}(x)=3(\sin x+\cos x)(3 \sin x \cos x-1) ;
$$




$$
\text { "takaci" — 2008/9/1 — 18:12 — page } 114 \text { — \#4 }
$$

- the graph of the given function $f$ is given on the Figure 1.

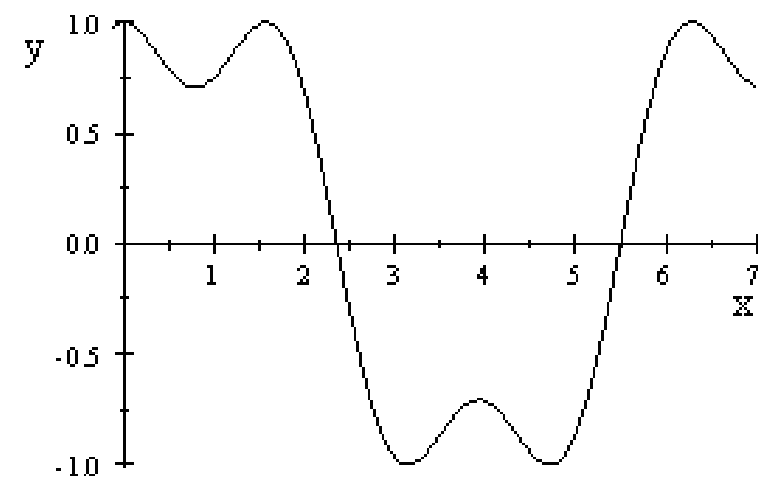

Figure 1

(2) Examine the function and draw its graph $g(x)=\sin 3 x-3 \sin x$. Instruction: Show that

- the given function can be written in the form: $g(x)=-4 \sin ^{3} x$.

In both examples we wanted to check the student's ability for transforming trigonometric equalities. All three groups had already done similar exercises a month earlier, (of course the two high school groups had done more exercises at school than the university students).

Three groups were tested. The first (high school) group and the second group (from the university) worked with the help of computer, while the third (high school) group did examining the functions without computer.

The instructions were given in order to help students in their calculations, because it is known that these trigonometric functions are difficult for examining. Therefore, they were almost never present in the students exams.

(1) Let us explain the reasons of giving the instructions of function $f$.

It is obvious that the instructions are given in the forms which are appropriate for determining the zeroes of functions, the extremes and, probably, the points of inflection.

The graph of the function $f$ was given on the interval $[0,7]$, in order to indicate that the smallest period is $2 \pi$.

The zeroes of $f$, on the interval $[0,2 \pi)$, are $x=\frac{3 \pi}{4}, x=\frac{7 \pi}{4}$, can be determined from the expressions given in the instructions and they can be 


$$
\text { "takaci" — 2008/9/1 — 18:12 — page } 115 \text { — \#5 }
$$

checked on the graph, expressing

$$
\frac{3 \pi}{4} \approx 2.36, \quad \frac{7 \pi}{4} \approx 5.5
$$

From the graph it can be seen that there are no more zeroes, resulting form a fact that there is no solution of the equation $\frac{\sin 2 x}{2}=1$.

The zeroes of the first derivatives $f^{\prime}$ on the interval $[0,2 \pi]$, are

$$
x=0, \quad x=\frac{\pi}{4}, \quad x=\frac{\pi}{2}, \quad x=\pi, \quad x=\frac{5 \pi}{4}, \quad x=\frac{3 \pi}{2},
$$

and they are determined from the expression and checked from the graph, expressing

$$
\frac{\pi}{4} \approx 0.79, \quad \frac{\pi}{2} \approx 1.57, \quad \pi \approx 3.14, \quad \frac{5 \pi}{4} \approx 3.93, \quad \frac{3 \pi}{2} \approx 4.71
$$

(2) The instructions for the function $g$ could help those students who are familiar with the functions

$$
g_{1}(x)=\sin x, \quad g_{2}(x)=\sin ^{3} x, \quad \text { or } \quad g_{3}(x)=-\sin x .
$$

Then the function $g$ given in the form $g(x)=-4 \sin ^{3} x$, could be examined easier. The graph for the function $g$ (Fig. 2) was not given.

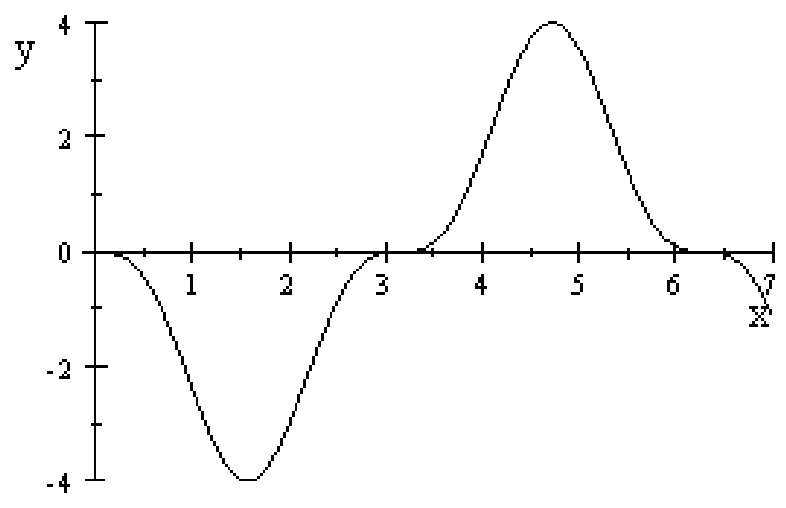

Figure 2

The students had one hour to finish their task. 


$$
\text { "takaci" — 2008/9/1 — 18:12 — page } 116 \text { — \#6 }
$$

\section{The results of the group I}

There were 28 students from high school who did exercises with the computer.

(1) The function $f$ was analyzed by 24 students. They considered each part as usual for examining the functions and the correct answers are the following:

$\begin{array}{lrr}\text { Proof } & 23 \text { students } & 82 \% \\ \text { Domain } & 19 \text { students } & 68 \% \\ \text { Period } & 22 \text { students } & 79 \% \\ \text { Odd, even } & 15 \text { students } & 54 \% \\ \text { Zeroes } & 20 \text { students } & 71 \% \\ \text { Extremes } & 22 \text { students } & 79 \% \\ \text { Saddle points } & 8 \text { students } & 28 \%\end{array}$

We were analyzing the students ability to work with trigonometric formulas and therefore we checked whether students proved the results given in instructions. They were asked to do that.

Let us remark that the students in this group wrote only correct answers. They said that they used the opportunity to have a graph in the first example, and they checked each obtained result on the graph.

Five students did not check the given instructions.

Even 9 students did not write anything about the domain. They had probably forgotten to consider this trivial part.

Six students did not write the main period. On the graph only one period $[0,2 \pi]$ could be seen, and probably it did not remind those students of the period.

8 students did not determine the zeroes of the function $f$. Only 6 students did not determine the extremes and they did not even determine the zeroes of the first derivative.

It is interesting that the same 4 students did not determine both the zero of the function and the zeroes of the first derivative. The other 4 students determined correctly the extremes, even though they did not determine the zeroes of function. Moreover, two students determined the zeroes of the first derivative but they did not say anything about extremes.

One student, considering the graph of $f$ made an interesting remark. The function $f$ has: 
- local minimum on the interval $\left(0, \frac{\pi}{2}\right)$ at $x=\frac{\pi}{4}$, adding the period,

- local maximum on the interval $\left(\pi, \frac{3 \pi}{2}\right)$ at $x=\frac{5 \pi}{4}$, adding the period,

- global minimums $x=0+2 k \pi, x=\frac{\pi}{2}+2 k \pi$,

- global maximums $x=\pi+2 k \pi, x=\frac{3 \pi}{2}+2 k \pi$.

Nobody in this group considered the monotonicity.

Only 15 (54\%) students considered the second derivative, for checking whether the zeroes of the first derivatives are extremes. The others made conclusions from the graph of $f$.

Eight students $(28 \%)$ had all correct answers except monotonicity, and another four students (14\%) also omitted saddle points.

(2) The function $g$ was analyzed by 21 students. They considered each part as usual for examining the functions and the correct answers are the following:

$\begin{array}{lll}\text { Proof } & 19 \text { students } & 68 \% \\ \text { Domain } & 15 \text { students } & 54 \% \\ \text { Period } & 15 \text { students } & 54 \% \\ \text { Odd, even } & 16 \text { students } & 57 \% \\ \text { Zeroes } & 16 \text { students } & 57 \% \\ \text { Extremes } & 20 \text { students } & 71 \% \\ \text { Saddle points } & 12 \text { students } & 42 \%\end{array}$

Only nine students drew the graph of the function $g$. The other students who examined almost each point exactly (after the test) said that they had just forgotten to do that because in the first example it had not been necessary, because the graph had been given.

The second function $g$ was examined by fewer students than the first function $f$. The reason was probably the function $a(x)=\sin 3 x$, and they did not pay attention to the instruction, because they made the function $g$ easier for examining than the function $f$.

The first and the second derivatives were not given, but they could be easily determined.

The eight students, four more than in the first example, determined saddle points. This was expected, since this is much more easier to do than in the first example. 


\section{The results of the group II}

There were 20 first year university students whose major was physics, and had the Calculus I from mathematics and they were taught by the help of computer.

(1) The function $f$ was analyzed by 18 (90\%) students. They considered each part as usual for examining the functions and the correct answers are the following:

$\begin{array}{lrr}\text { Proof } & 9 \text { students } & 45 \% \\ \text { Domain } & 16 \text { students } & 80 \% \\ \text { Period } & 17 \text { students } & 85 \% \\ \text { Odd, even } & 12 \text { students } & 60 \% \\ \text { Zeroes and sign } & 9 \text { students } & 45 \% \\ \text { Extremes } & 11 \text { students } & 55 \% \\ \text { Saddle points } & 4 \text { students } & 20 \% \\ \text { Asymptotes } & 9 \text { students } & 45 \% \\ \text { Monotonicity } & 8 \text { students } & 40 \%\end{array}$

It is interesting to mention that one student gave the following answers:

$f^{\prime}(x)=0$, for $x=1$, and $x=0$.

$f$ is increasing for $x \in(1,2) \cup(3,4) \cup(5,6)$;

$f$ is decreasing for $x \in(0,1) \cup(2,3) \cup(4,5)$.

She explained that by just looking at the graph it can be seen that the first derivative of the function $f$ has zeroes at approximately $x=1, x=2$, $x=3, x=4, x=5, x=6$, but from the first derivative she could check this, of course, only in the case of $x=0$.

(2) The function $g$ was analyzed by $16(80 \%)$ students. They considered each part as usual for examining the functions and the correct answers are the following: 


$$
\text { "takaci" — 2008/9/1 — 18:12 — page } 119-\# 9
$$

$\begin{array}{lrr}\text { Proof } & 12 \text { students } & 60 \% \\ \text { Domain } & 15 \text { students } & 75 \% \\ \text { Period } & 14 \text { students } & 70 \% \\ \text { Odd, even } & 12 \text { students } & 60 \% \\ \text { Zeroes and sign } & 13 \text { students } & 65 \% \\ \text { Extremes } & 15 \text { students } & 75 \% \\ \text { Saddle points } & 9 \text { students } & 45 \% \\ \text { Asymptotes } & 9 \text { students } & 45 \% \\ \text { Monotonicity } & 10 \text { students } & 50 \%\end{array}$

In the second group seven students (35\%) did each point correctly in both exercises, one $(5 \%)$ student did each point correctly except monotonicity and one student did each point correctly except the second zero $x=\frac{7 \pi}{4}$ in the first example.

The students from the university are almost a year older than the high school students and they considered monotonicity and the sign of the second derivative.

Thirteen students $(65 \%)$ considered asymptotes and they got the expected results - that there were no asymptotes, except one who wrote: In the second group seven students (35\%) did each point correctly in both exercises, one (5\%) student did each point correctly except monotonicity and one student did each point correctly except the second zero $x=\frac{7 \pi}{4}$ in the first example.

The students from the university are almost a year older than the high school students and they considered monotonicity and the sign of the second derivative.

Thirteen students $(65 \%)$ considered asymptotes and they got the expected results - that there were no asymptotes, except one who wrote:

$$
\lim _{x \rightarrow \infty} \sin ^{3} x+\cos ^{3} x=1 .
$$

Two students did only some transformations, but they did not finish that.

\section{The results of the group III}

There were 22 students from high school who did not do exercises with the computer.

(1) The first function $f$ was considered by $12(55 \%)$ students and the results are following: 


$$
\text { "takaci" — 2008/9/1 — 18:12 — page } 120 \text { — \#10 }
$$

$\begin{array}{lrr}\text { Proof } & 7 \text { students } & 32 \% \\ \text { Domain } & 12 \text { students } & 55 \% \\ \text { Period } & 12 \text { students } & 55 \% \\ \text { Odd, even } & 4 \text { students } & 18 \% \\ \text { Zeroes } & 2 \text { students } & 9 \% \\ \text { Extremes } & 4 \text { students } & 18 \% \\ \text { Saddle points } & 3 \text { students } & 14 \%\end{array}$

Students got the graph of the function, but they still were not able to determine all zeroes and all extremes. They were not familiar with the use of the graph.

(2) The second function was considered by 15 (68\%) students and the results are following:

$\begin{array}{lrr}\text { Proof } & 9 \text { students } & 41 \% \\ \text { Domain } & 15 \text { students } & 68 \% \\ \text { Period } & 15 \text { students } & 68 \% \\ \text { Odd, even } & 13 \text { students } & 59 \% \\ \text { Zeroes } & 8 \text { students } & 36 \% \\ \text { Extremes } & 8 \text { students } & 36 \% \\ \text { Saddle points } & 5 \text { students } & 22 \%\end{array}$

It can be remarked that only eight students did zeroes and extremes correctly. The others considered the function $g(x)=\sin 3 x-3 \sin x$, and the first derivative in the form $g^{\prime}(x)=3 \cos 3 x-3 \cos x$, and of course they had problems determining their zeroes of corresponding equations. Five students $(23 \%)$ drew the graph of function.

Four students (18\%) handed the blank papers only with their names written and the other 18 students started applying trigonometric identities, but only five (23\%) of them did transformations for both functions correctly.

In this group only two students $9 \%$ had all answers correct. Both of them drew the graph of the second function. One of these two students even examined monotonicity, and he was the only one who considered that.

The other three students $14 \%$ answered almost correctly, but they had a few mistakes, they omitted to mention the one zero of function, two extremes and the saddle points in the first example, and the proof in the second example. 


$$
\text { "takaci" — 2008/9/1 — 18:12 — page } 121 \text { — \#11 }
$$

\section{The comparison of results}

Let us first remark that in the first and second group more students worked on the first example, but in the third group more students worked on the second example. The second example is in fact the easier one for the analysis.

(1) The following table represents the results of all three groups for the function $f$ :

$$
\text { I group II group III group }
$$

$\begin{array}{lllr}\text { Proof } & 82 \% & 45 \% & 32 \% \\ \text { Domain } & 68 \% & 80 \% & 55 \% \\ \text { Period } & 79 \% & 85 \% & 55 \% \\ \text { Odd, even } & 54 \% & 60 \% & 18 \% \\ \text { Zeroes } & 71 \% & 45 \% & 9 \% \\ \text { Extremes } & 79 \% & 55 \% & 18 \% \\ \text { Saddle points } & 28 \% & 20 \% & 14 \%\end{array}$

(2) The following table represents the results of all three groups for the function $g$ :

$$
\text { I group II group III group }
$$

$\begin{array}{llll}\text { Proof } & 68 \% & 60 \% & 41 \% \\ \text { Domain } & 54 \% & 75 \% & 68 \% \\ \text { Period } & 54 \% & 70 \% & 68 \% \\ \text { Odd, even } & 57 \% & 60 \% & 59 \% \\ \text { Zeroes } & 57 \% & 65 \% & 36 \% \\ \text { Extremes } & 71 \% & 75 \% & 36 \% \\ \text { Saddle points } & 42 \% & 45 \% & 22 \%\end{array}$

Comparing the results of the considered three groups it can be seen that:

- In the first example the first high school group had the best results, in correctly determining the most difficult parts, such as the proofs, the zeroes, and extremes.

- In the second example the university students showed better results (except the proofs).

- The third group had good results in trivial analysis, (domain, period, oddity), but the difference between this group and the first two groups is in 


$$
\text { "takaci" — 2008/9/1 — 18:12 — page } 122 \text { — \#12 }
$$

determining zeroes of the functions and of the derivatives, in fact in solving corresponding trigonometric equations. The graph of function $f$ could not help them as much as it did the other students.

It can be concluded that the students who had been taught by computer gained better knowledge than the students who examined functions in a usual way, which means that they first examined the function and then they drew the graph.

The results of the third group confirmed the teacher's previous opinion that the trigonometric functions, if they are taught classically, are not appropriate for analysis in high school (probably not even at the university, either), for the students exams, because this is really difficult task for them. Yet, the fact that the results of the first two groups are really excellent provides the possibility that the students can be given to examine trigonometric functions in their written tasks and exams.

We can say that the use of computer provides better understanding of the connections between the graph of functions and the properties of function obtained by calculations.

The results of these two groups show two main points.

(1) The students obtain better knowledge if they use computer as a help for the problems in examining trigonometric functions. Let us remember that during the lessons the students combined the classical approach with the results obtained by computer in order to understand the connections between the graph of functions and the properties of function obtained by calculations.

(2) The questionnaire was given in a different way than usually, because in both examples the instructions are given. The above results show that these instructions helped those students with good knowledge in considering contents. The help of computer enabled this.

(3) Working with the computer the students got the possibility to use the graphs of the function in the proper way.

\section{References}

[1] J. Schmeelk, Dj. Takači, A. Takači, Elementary Analysis through Examples and Exercises, Kluwer Academic Publishers, Dordrecht/Boston/London, 1995.

[2] Dj. Takači, D. Pešić, The Continuity of Functions in Mathematical Education-Visualization method, Nastava matematike (Teaching mathematics) 49, no. 3-4, Belgrade (2004) (in Serbian). 


$$
\text { "takaci" — 2008/9/1 — 18:12 — page } 123 \text { — \#13 }
$$

[3] Dj. Takači, D. Pešić, J. Tatar, An introduction to the Continuity of functions using Scientific Workplace, The Teaching of Mathematics VI, no. 2, Belgrade (2003), 105-112.

[4] Dj. Takači, D. Pešić, J. Tatar, On the continuity of functions, International Journal of Mathematical Education in Science and Technology 37, no. 7, Taylor \& Frencis (15 October 2006), 783-791.

[5] Dj. Takači, D. Herceg, R. Stojković, Possibilities and limitations of Scientific Workplace in studying trigonometric functions, The Teaching of Mathematics VIII, no. 2, Društvo matematicara Srbije, Beograd (2005), ISSN: 1451-4966.

[6] D. Tall, The Transition to Advanced Mathematical Thinking: Functions, Limits, Infinity, and Proof, in: Handbook of Reseach on Mathematcs Teaching and Learning, (D. A. Grouws, ed.), Macmillan, New York, 1991, 495-511.

[7] D. Tall, Resent Developements in the Use of Computer to Visualize and Symbolize Calculus Concepts, The Laboratory Approach to Teaching Calculus, M. A. A. Notes 20 (1991), 15-25.

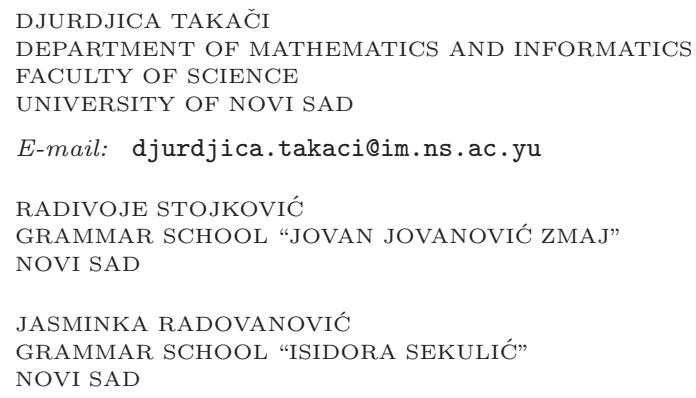

(Received September, 2007) 